\title{
PEMBERDAYAAN MASYARAKAT MELALUI PENYULUHAN PERILAKU HIDUP BERSIH DAN SEHAT UNTUK MENINGKATKAN KUALITAS KESEHATAN MASYARAKAT
}

\section{COMMUNITY EMPOWER THROUGH COUNSELING OF THE BEHAVIOUR OF CLEAN AND HEALTHY LIFESTYLESTO IMPROVE COMMUNITY HEALTH QUALITY}

\author{
${ }^{1)}$ Hairudin La Patilaiya, ${ }^{2)}$ Hamidah Rahman \\ ${ }^{1,2)}$ Program Studi Kesehatan Masyarakat \\ Fakultas Ilmu Kesehatan Universitas Muhammadiyah Maluku Utara \\ Jalan K.H Ahmad Dahlan No. 100 Kota Ternate \\ Email: hamidahr42@gmail.com
}

\begin{abstract}
ABSTRAK
Upaya untuk meningkatkan derajat kesehatan masyarakat menjadi hal yang sangat penting untuk mencapai taraf hidup yang lebih baik. Salah satu strategi untuk mencapai derajat kesehatan masyarakat adalah dengan memberikan pemahaman dan kesadaran masyarakat untuk menerapkan pola hidup bersih yang dimulai dari tingkat keluarga atau rumah tangga, lingkungan sekolah dan masyarakat luas. Program pengabdian masyarakat yang diinisiasi oleh Majelis Kesehatan Umum dan Pelayanan Sosial Pimpinan Wilayah Muhammadiyah Maluku Utara ini bertujuan untuk meningkatkan pengetahuan dan pemahaman masyarakat untuk memiliki kesadaran tinggi dan potensi diri untuk menjaga kesehatan melalui pengenalan Perilaku Hidup Bersih dan Sehat (PHBS). Metode pelaksanaan adalah dengan (1) penyuluhan tentang praktek PHBS di tingkat rumah tangga, (2) penyuluhan tentang PHBS di tingkat institusi pendidikan, (3) praktek cuci tangan yang benar pada murid sekolah, dan (4) pemberdayaan masyarakat dengan kegiatan menjaga kebersihan lingkungan. Kegiatan ini melibatkan seluruh masyarakat desa Posi-posi berjumlah 84 rumah tangga dan 60 murid SD Inpres Posi-posi. Hasil kegiatan menunjukkan ada peningkatan pengetahuan rumah tangga dan murid SD tentang PHBS dan seluruh murid telah mampu untuk mencuci tangan dengan benar.
\end{abstract}

Kata Kunci: Pemberdayaan Masyarakat, Penyuluhan, Cuci tangan, PHBS

\section{ABSTRACT}

To achieve a better standard of living, it need an effort to promote public health. One strategy to achieve the level of public health is to provide an understanding and awareness of the community to implement a clean lifestyle that begin at the family level, the environment, and society at large. The community service program initiated by the General Health and Social Services Council of Muhammadiyah North Maluku Regional Leadership was aimed to increase the knowledge and understanding of the community to have high awareness and potential to maintain health through the introduction of Clean and Healthy Behavior (PHBS). The method of implementations was to (1) the counseling of the practice of PHBS at the household level, (2) counseling of PHBS in the level of educational institutions, (3) practice proper hand washing at students, and (4) community empowerment to maintain environmental hygiene. This activities involved the whole community of Posi-posi representing 84 households, and 60 students of SD Inpres Posi-posi. The results show that there was an increased knowledge of households and students about PHBS, and all students have been able to wash their hands properly. The program was also assisted by public health students so that they can practice their knowledge gained in college.

Keywords: Community empowerment, Counseling, Washing hands, PHBS 
Hairudin La Patilaiya, Hamidah Rahman

Pemberdayaan Masyarakat Melalui Penyuluhan Perilaku Hidup Bersih Dan Sehat Untuk Meningkatkan

Kualitas Kesehatan Masyarakat

Submitted : 4 April 2018 Revision: 22 April 2018 Accepted : 25 Juni 2018

\section{PENDAHULUAN}

Program Perilaku Hidup Bersih dan Sehat (PHBS) adalah salah satu upaya promosi kesehatan yang bertujuan agar setiap orang dapat tinggal di lingkungan yang bersih dan sehat dengan menciptakan suatu kondisi yang kondusif bagi perorangan, keluarga, kelompok dan masyarakat. Hal ini bertujuan untuk meningkatkan pengetahuan, sikap dan perilaku agar dapat menerapkan cara-cara hidup sehat dalam rangka menjaga, memelihara, dan meningkatkan kesehatan (Raksanagara \& Raksanagara, 2015). Salah satu misi promosi kesehatan adalah memberdayakan individu, keluarga dan masyarakat untuk hidup sehat melalui program pemberdayaan masyarakat. Oleh sebab itu sasaran promosi kesehatan dapat melalui pemberdayaan individu, pemberdayaan keluarga dan pemberdayaan kelompok atau masyarakat (Kemenkes RI, 2011a).

Pemberdayaan masyarakat merupakan bagian yang sangat penting dan bahkan dapat dikatakan sebagai ujung tombak untuk promosi kesehatan. Pemberdayaan akan lebih berhasil jika dilaksanakan melalui kemitraan serta menggunakan metode dan teknik yang tepat (Kemenkes RI, 2011a). Penyuluhan kesehatan adalah salah satu metode yang dapat diterapkan untuk tindakan preventif guna mengingatkan masyarakat pentingnya menjaga kesehatan. Melalui metode penyuluhan maka pemeliharaan kesehatan masyarakat dapat dimulai dari kesadaran setiap individu, keluarga, kelompok dan masyarakat luas. Kegiatan penyuluhan langsung ke masyarakat terutama masyarakat yang masih jauh dari jangkauan media informasi maupun fasilitas

kesehatan akan dapat membantu masyarakat mendapatkan informasi kesehatan, maka dengan kegiatan pengabdian masyarakat ini dapat mendukung hak literasi informasi kesehatan setiap individu (Prasanti \& Fuady, 2017). Demikian pula dengan literasi informasi kesehatan sangat mendukung untuk kegiatan pemberdayaan (Word Health Organization, n.d.).

Pemerintah melalui Kementerian Kesehatan sebetulnya telah memperkenalkan pelaksanaan Perilaku Hidup Bersih dan Sehat (PHBS) sejak tahun 1996, akan tetapi cakupan pelaksanaan PHBS diketahui masih rendah. Untuk itu Kementerian Kesehatan membuat aturan dan arahan pelaksanaan PHBS melalui Peraturan Menteri Kesehatan Republik Indonesia Nomor: 2269/MENKES/PER/XI/2011 tentang Pedoman Pembinaan Perilaku Hidup Bersih dan Sehat. Sebagai penjabaran dari Permenkes tersebut, dalam buku pedoman pembinaan PHBS disebutkan bahwa derajat kesehatan masyarakat yang masih belum optimal pada hakikatnya dipengaruhi oleh kondisi lingkungan, perilaku masyarakat dan sistem pelayanan kesehatan yang masih kurang optimal. Hasil penelitian menunjukkan bahwa determinan utama dari kurang optimalnya derajat kesehatan masyarakat selain disebabkan oleh kondisi lingkungan yang kurang sehat, hal ini juga disebabkan oleh perilaku masyarakat (Kemenkes RI, 2011b).

Dari beberapa laporan riset kesehatan sebelumnya diketahui bahwa rumah tangga yang telah menerapkan PHBS baru mencapai $38,7 \%$ yang menunjukkan angka yang belum optimal. Demikian pula pada tingkatan institusi pendidikan, instansi tempat kerja, di tempat umum dan pada fasilitas kesehatan, praktek PHBS juga belum terlaksana sebagaimana mestinya (Kemenkes RI, 2011b). Berdasarkan hasil kajian berbasis data-data tersebut di atas, maka tim penulis melakukan

JPPM ISSN: 2549 - 8347 (Online) ISSN: 2579 - 9126 (Print) Vol. 2 No. 2 September 2018 
Hairudin La Patilaiya, Hamidah Rahman

Pemberdayaan Masyarakat Melalui Penyuluhan Perilaku Hidup Bersih Dan Sehat Untuk Meningkatkan

Kualitas Kesehatan Masyarakat

program pengabdian masyarakat ini untuk memperkuat gerakan dan peran serta masyarakat untuk melaksanakan praktek PHBS di tatanan rumah tangga dan institusi pendidikan yaitu di sekolah dasar.

Desa Posi-posi terletak di Kecamatan Gane Barat Utara yang berada di wilayah kabupaten Halmahera Selatan Provinsi Maluku Utara (Badan Pusat Statistik Kabupaten Halmahera Selatan, 2017) dengan lokasi seperti ditunjukkan pada gambar 1 . Jarak Kecamatan Gane Barat Utara dari Kota Ternate sekitar $176 \mathrm{~km}$ dan dapat ditempuh menggunakan transportasi laut dengan lama tempuh sekitar 1 jam dari Kota Ternate.

Fasilitas kesehatan seperti puskesmas induk berjarak sekitar $20 \mathrm{~km}$ dari Desa Posi-posi. Praktek tenaga kesehatan di desa tersebut dilayani oleh seorang bidan. Jumlah kepala keluarga (KK) di desa ini berjumlah $90 \mathrm{KK}$ dengan penghasilan utama masyarakat adalah sebagai petani. Di desa ini hanya terdapat 1 buah Sekolah Dasar (SD) dan 1 buah Sekolah Menegah Pertama (SMP). Dengan pertimbangan bahwa Desa Posi-posi jauh dari jangkauan puskesmas dan akses literasi informasi kesehatan juga masih terbatas maka desa ini dijadikan sebagai sasaran untuk melaksanakan pengabdian masyarakat. Kegiatan penyuluhan PHBS di desa ini diharapkan dapat meningkatkan derajat kesehatan masyarakat setempat.

Kegiatan ini bertujuan untuk meningkatkan pengetahuan dan pemahaman masyarakat mengenai perilaku PHBS di tingkat rumah tangga dan PHBS di institusi pendidikan yaitu pada siswa SD, mempraktekkan cara mencuci tangan yang benar pada siswa SD sebagai salah satu cara agar terhindar dari penyakit menular serta memberdayakan masyarakat desa Posi-posi untuk menjaga kesehatan lingkungan.

\section{METODE KEGIATAN}

Kegiatan ini dilaksanakan dengan metode yang disesuaikan dengan kondisi lingkungan masyarakat di Desa Posi-posi, yaitu:

1. Melakukan penyuluhan dan tanya jawab interaktif dengan masyarakat. Kegiatan diikuti oleh masyarakat setempat dan difasilitasi oleh aparat desa Posi-posi.

2. Melakukan penyuluhan di sekolah dasar untuk memperkenalkan dan memberikan pemahaman ke siswa sejak dini mengenai pola hidup bersih dan sehat disertai dengan praktek cara mencuci tangan yang benar untuk setiap murid.

3. Kerja bakti bersih lingkungan dengan masyarakat sebagai bentuk bakti sosial dan pemberdayaan masyarakat untuk menjaga dan meningkatkan kualitas lingkungan tempat tinggal mereka.

Kelompok sasaran atau mitra untuk kegiatan ini adalah semua rumah tangga di wilayah desa Posi-posi yang diikuti oleh kepala keluarga atau salah satu anggota keluarga berjumlah 84 orang. Mitra ini dilibatkan untuk kegiatan penyuluhan perilaku PHBS di rumah tangga dan kegiatan menjaga kesehatan lingkungan. Untuk kegiatan penyuluhan PHBS di institusi pendidikan dan pengenalan cara mencuci tangan yang benar melibatkan siswa sebagai kelompok sasaran yaitu kelas III, IV dan V di SD Inpres Posi-posi yang diikuti 90 orang siswa.

\section{HASIL DAN PEMBAHASAN}

Hasil kegiatan penyuluhan tentang pengetahuan PHBS pada masyarakat di desa Posi-posi menunjukkan bahwa dengan penyuluhan dapat meningkatkan pengetahuan setiap rumah tangga terhadap perilaku PHBS. Hal ini tergambar dari hasil evaluasi yang mengukur tingkat pengetahuan tentang PHBS di tingkat rumah tangga melalui metode pengujian pre test dan post test. Dengan kegiatan penyuluhan dapat meningkatkan pengetahuan masyarakat tentang PHBS di

JPPM ISSN: 2549 - 8347 (Online)

ISSN: 2579 - 9126 (Print)

Vol. 2 No. 2 September 2018 
Hairudin La Patilaiya, Hamidah Rahman

Pemberdayaan Masyarakat Melalui Penyuluhan Perilaku Hidup Bersih Dan Sehat Untuk Meningkatkan

Kualitas Kesehatan Masyarakat

rumah tangga sebesar $37,2 \%$ seperti ditunjukkan pada gambar 1. Metode penyuluhan memberikan pengaruh secara bermakna terhadap tingkat pengetahuan dan dengan pengetahuan yang dimiliki dapat diterapkan dalam kehidupan sehari-hari (Anggoro, Harmianto, \& Yuwono, 2018) termasuk penerapan dalam mencapai derajat kesehatan yang baik.

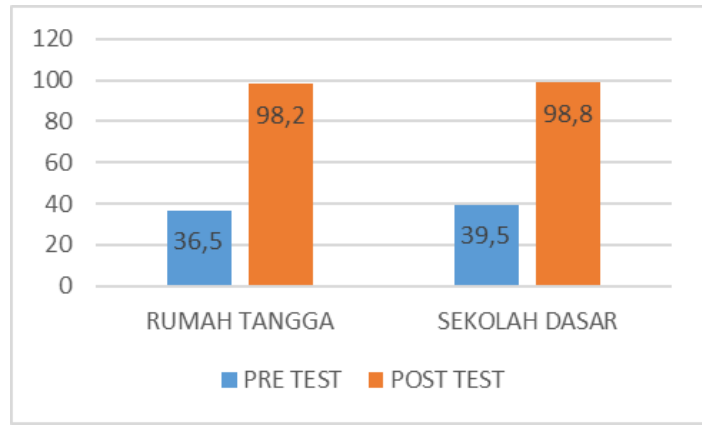

Kegiatan penyuluhan yang dilanjutkan dengan diskusi interaktif dilakukan pada kelompok masyarakat di desa Posi-posi meliputi pengenalan konsep PHBS dan pentingnya melakukan PHBS di tingkat rumah tangga masing-masing. Pada kegiatan ini masyarakat diyakinkan dari manfaat melakukan PHBS di tingkat rumah tangga. Jika PHBS dilaksanakan dengan baik dapat memberikan manfaat langsung dalam keluarga yaitu meningkatkan taraf hidup keluarga karena dapat menekan pengeluaran biaya berobat sehingga pengeluaran biaya rumah tangga dapat lebih difokuskan untuk pemenuhan gizi keluarga, biaya pendidikan atau dimanfaatkan untuk modal usaha. Jika keluarga dapat menjalankan suatu usaha maka otomatis akan meningkatkan pendapatan keluarga. Selain itu karena setiap anggota keluarga meningkat kesehatannya dan tidak mudah sakit maka anak akan tumbuh sehat dan cerdas dan produktivitas kerja setiap anggota keluarga akan meningkat. Dari hasil diskusi interaktif masyarakat menyetujui informasi dan manfaat langsung dari pelaksanaan PHBS di keluarga masing-masing.

Hasil yang dicapai dari kegiatan penyuluhan praktek PHBS di tingkat institusi pendidikan yang dilakukan di Sekolah Dasar Inpres Posi-posi menunjukkan terdapat peningkatan pengetahuan siswa sebesar $40 \%$ seperti ditunjukkan pada gambar 2. Kegiatan penyuluhan merupakan salah satu media untuk menyampaikan informasi kesehatan terutama pada lokasi yang masih jauh dari jangkauan media informasi melalui akses literasi informasi kesehatan (Prasanti \& Fuady, 2017).

Setelah kegiatan penyuluhan pada anak sekolah dasar lalu dilanjutkan dengan praktek mencuci tangan dengan benar. Sebelum diajarkan cara mencuci tangan yang benar, pada umumnya siswa belum bisa mempraktekkan cara cuci tangan dengan benar. Dengan mengajarkan cara mencuci tangan yang benar maka seluruh siswa dapat mempraktekkan mencuci tangan dengan benar seperti yang ditunjukkan pada gambar 3. Pada kegiatan penyuluhan para siswa aktif berinteraksi dengan tim penyuluh dan tertarik untuk mempraktekkan perilaku mencuci tangan yang benar.

Tim pelaksana pengabdian masyarakat menjadikan murid usia sekolah dasar sebagai sasaran pengenalan perilaku PBHS dengan pertimbangan bahwa praktek perilaku PHBS harus sudah diperkenalkan pada usia dini agar mereka sejak awal telah mengetahui perilaku hidup sehat yang baik. Selain itu hasil penelitian dari United Nations International Children's Emergency Fund (UNICEF) yaitu (Brumana, Arroyo, Schwalbe, Lehtimaki, \& Hipgrave, 2017) menunjukkan bahwa untuk mencegah penyakit tidak menular (PTM) dikemudian hari harus dilakukan pencegahan berbasis siklus hidup manusia termasuk pencegahan yang dilakukan sejak usia dini yaitu dengan cara memperkenalkan pola hidup sehat pada usia anak sekolah. Selain itu 
Hairudin La Patilaiya, Hamidah Rahman

Pemberdayaan Masyarakat Melalui Penyuluhan Perilaku Hidup Bersih Dan Sehat Untuk Meningkatkan

Kualitas Kesehatan Masyarakat

dengan menerapkan praktek PHBS di sekolah dasar akan dapat menunjang prestasi belajar siswa.

Kegiatan pemberdayaan masyarakat telah dilakukan dengan hasil terlihat partisipasi masyarakat untuk bersama-sama terlibat dalam menjaga kebersihan lingkungan dan mendapat tanggapan positif dari masyarakat. Hal ini ditunjukkan dengan kesiapan masyarakat untuk terlibat dalam kerja bakti membersihkan lingkungan dan memfasilitasi pengadaan dan pembuangan sampah secara sukarela. Masyarakat juga menyetujui bahwa dengan lingkungan tempat tinggal yang bersih mereka dapat terhindar dari penyakit. Demikian pula masyarakat menyadari bahwa menjaga lingkungan tempat tinggal secara bersamasama akan memudahkan untuk mencapai derajat kesehatan masyarakat yang lebih baik.

Pemberdayaan masyarakat adalah suatu upaya untuk membangun daya dengan mendorong, memotivasi dan membangkitkan kesadaran akan potensi yang dimiliki serta berupaya mengembangkannya dan juga memperkuat potensi yang dimiliki oleh masyarakat (Minarni, Utami, \& Prihatiningsih, 2017). Dengan kegiatan pemberdayaan masyarakat di desa Posi-posi untuk menjaga dan meningkatkan kesehatan lingkungan adalah merupakan bagian yang sangat penting dan bahkan dapat dikatakan sebagai ujung tombak untuk promosi kesehatan di masyarakat.

Materi penyuluhan pada masyarakat desa Posi-posi adalah pengertian dan manfaat rumah tangga ber-PHBS. Rumah tangga PHBS adalah rumah tangga yang melakukan 10 (sepuluh) indikator program PHBS, yaitu: (1) pertolongan persalinan oleh tenaga kesehatan, (2) memberi bayi Air Susu Ibu (ASI) eksklusif, (3) menimbang balita setiap bulan,(4) menggunakan air bersih, (5) mencuci tangan dengan air bersih dan sabun, (6) menggunakan jamban sehat, (7) memberantas jentik di rumah sekali seminggu, (8) makan buah dan sayur di rumah setiap hari, (9) melakukan aktivitas fisik setiap hari, dan (10) tidak merokok di dalam rumah.

Penyuluhan PHBS di institusi pendidikan yaitu di Sekolah Dasar Inpres Posi-posi dilakukan bersama dengan praktek cara mencuci tangan yang benar. Materi yang diberikan antara lain: (1) mencuci tangan menggunakan sabun, (2) mengonsumsi makanan dan minuman sehat, (3) menggunakan jamban sehat, (4) membuang sampah di tempat sampah, (5) tidak merokok, (6) tidak mengonsumsi narkotika, alkohol, psikotropika dan zat adiktif lainnya, (7) tidak meludah di sembarang tempat, memberantas jentik nyamuk dan lain-lain.

Materi penyuluhan PHBS di institusi pendidikan dan praktek cuci tangan yang benar untuk siswa dimaksudkan antara lain agar para siswa dapat mengenali penyakit yang dapat ditimbulkan akibat tidak mencuci tangan. Dijelaskan pula bahwa dengan hidup sehat dapat meningkatkan prestasi belajar karena kondisi tumbuh kembang siswa juga baik sehingga mampu menyerap pelajaran yang diberikan oleh para guru di sekolah. Pentingnya menekankan perilaku cuci tangan ke murid sejak usia dini adalah karena berdasarkan hasil penelitian menunjukkan bahwa ada hubungan antara perilaku cuci tangan murid dengan angka kejadian kecacingan (Umar, 2008). Selanjutnya kejadian kecacingan akan menyebabkan stunting dan kemampuan belajar siswa yang menurun.

Untuk mengetahui tingkat keberhasilan dari pelaksanaan program pengabdian masyarakat ini maka perlu dilakukan pemantauan dan evaluasi. Pemantauan dilakukan selama pelaksanaan hingga selesai kegiatan dan dilanjutkan dengan evaluasi kegiatan. Metode yang digunakan untuk mengetahui keberhasilan kegiatan penyuluhan adalah

JPPM ISSN: 2549 - 8347 (Online)

ISSN: 2579 - 9126 (Print)

Vol. 2 No. 2 September 2018 
Hairudin La Patilaiya, Hamidah Rahman

Pemberdayaan Masyarakat Melalui Penyuluhan Perilaku Hidup Bersih Dan Sehat Untuk Meningkatkan

Kualitas Kesehatan Masyarakat

dengan mengukur tingkat pengetahuan tentang

PHBS seperti yang telah diuraikan di atas.

Dari hasil pemantauan untuk ketiga program kerja yang dilakukan, yaitu penyuluhan PHBS di rumah tangga pada masyarakat, penyuluhan dan praktek PHBS pada siswa sekolah dasar dan pemberdayaan masyarakat untuk meningkatkan kesehatan lingkungan diketahui bahwa tingkat partisipasi masyarakat untuk kegiatan ini cukup baik. Hal ini dapat diketahui dari tingkat partisipasi masyarakat yang aktif dalam menyimak dan berdiskusi dengan tim penyuluhan. Masyarakat antusias menanyakan masalah kesehatan yang menyangkut PHBS. Demikian pula penyuluhan PHBS dan praktek mencuci tangan yang benar di SD Inpres Posi-posi sangat mendapat perhatian dari murid sekolah. Hal ini tampak dari kemampuan siswa untuk mengulangi praktek mencuci tangan yang benar telah berhasil dilakukan. Demikian pula untuk kegiatan membersihkan lingkungan ditunjukkan dengan partisipasi masyarakat untuk terlibat langsung membersihkan lingkungan tempat tinggal mereka.

Untuk melihat dampak nyata dari kegiatan program pengenalan PHBS dilakukan evaluasi kegiatan yang telah dilaksanakan. Sistem evaluasi yang dilakukan pada kegiatan ini adalah dengan turun meninjau ke beberapa rumah penduduk sebelum meninggalkan untuk lokasi untuk mengakhiri kegiatan.Tim pelaksana mengunjungi beberapa rumah warga untuk melihat pelaksanaan rumah tangga berPHBS. Demikian pula tim ke lokasi sekolah dasar untuk melihat perilaku siswa dalam PHBS. Hasil evaluasi menunjukkan bahwa sebagian besar masyarakat telah berusaha untuk menerapkan perilaku PHBS di rumah masing-masing sedangkan murid di Sekolah Dasar Inpres Posi-posi telah memiliki perilaku cuci tangan yang benar dan menjaga kebersihan sekolah.
Program pengabdian masyarakat dengan kegiatan penyuluhan praktek PHBS dapat dilanjutkan untuk diperkenalkan pada tatanan tempat kerja, di tempat fasilitas umum dan fasilitas pelayanan kesehatan. Rumah tangga dan di lingkungan sekolah merupakan tempat yang strategis untuk memperkenalkan dan mempraktekkan PHBS sebagai sarana promosi untuk meningkatkan derajat kesehatan Indonesia, sehingga kegiatan serupa dengan ini dapat diterapkan di desa lainnya terutama untuk lokasi yang masih sulit dijangkau oleh media sehingga setiap masyarakat memperoleh literasi informasi kesehatan yang memadai. Kegiatan serupa akan diprioritaskan terutama di desa yang masih minim terhadap literasi informasi kesehatan dan desa yang jauh dari jangkauan fasilitas kesehatan.

Kegiatan pengabdian dan pemberdayaan kepada masyarakat ini juga melibatkan beberapa mahasiswa dari program studi Kesehatan Masyarakat Universitas Muhammadiyah Maluku Utara. Tujuannya adalah agar para mahasiswa juga dapat memberikan contoh dan terlibat langsung pada pemberdayaan masyarakat untuk meningkatkan derajat kesehatan masyarakat. Selain itu kegiatan ini dapat sebagai media mahasiswa untuk mempraktekkan ilmu yang telah diperoleh di bangku kuliah.

\section{SIMPULAN}

Kegiatan pengabdian masyarakat ini dapat memberikan dampak bagi peningkatan derajat kesehatan masyarakat di desa Posi-posi antara lain meningkatkan pengetahuan masyarakat tentang perilaku PHBS, mengetahui dan menyadari akan pentingnya ber-PHBS, siswa Sekolah Dasar Inpres Posiposi mengetahui PHBS dan dapat mempraktekkan perilaku mencuci tangan yang baik sehingga akan terhindar dari berbagai penyakit, masyarakat di desa Posi-posi menyadari dan mau terlibat langsung untuk 
Hairudin La Patilaiya, Hamidah Rahman

Pemberdayaan Masyarakat Melalui Penyuluhan Perilaku Hidup Bersih Dan Sehat Untuk Meningkatkan

Kualitas Kesehatan Masyarakat

meningkatkan dan menjaga kebersihan lingkungan sebagai bentuk pemberdayaan masyarakat untuk mencapai kualitas kesehatan yang lebih baik.

\section{UCAPAN TERIMA KASIH}

Penulis mengucapkan terima kasih kepada Majelis Kesehatan Umum dan Pelayanan Sosial Pimpinan Wilayah Muhammadiyah Maluku Utara atas bantuan dan dukungan pelaksanaan kegiatan pengabdian masyarakat yang dilaksanakan pada April 2017. Terkhusus, ucapan terima kasih juga kepada para mahasiswa (Sukiwan Buton, Taufik Yunus, Supriono, Siti Masyitah Ibrahim, Sitna Dewi Achmad) dari Program Studi Kesehatan Masyarakat Universitas Muhammadiyah Maluku Utara atas partisipasinya pada kegiatan pengabdian masyarakat ini.

\section{DAFTAR PUSTAKA}

Anggoro, S., Harmianto, S., \& Yuwono, P. D. (2018). Upaya Meningkatkan Kemampuan Pedagogik Guru Melalui Pelatihan Pembelajaran Tematik Sains Menggunakan Inquiry Learning Process dan Science Activity Based Daily Life. Jurnal Pengabdian Dan Pemberdayaan Masyarakat, 2(1), 29-35.

Badan Pusat Statistik Kabupaten Halmahera Selatan. (2017). Statistik kesejahteraan rakyat kabupaten Halmahera Selatan Tahun 2017. Jakarta: Badan Pusat Statistik.

Brumana, L., Arroyo, A., Schwalbe, N. R., Lehtimaki, S., \& Hipgrave, D. B. (2017). Maternal and Child Health Services and An Integrated, Life-cycle Approach to the Prevention of Non-communicable Diseases. BMJ Global Health, 2(3), e000295. https://doi.org/10.1136/bmjgh2017-000295.
Departemen Kesehatan Republik Indonesia. (2009). Rumah tangga sehat dengan perilaku hidup bersih dan sehat. Jakarta: Departemen Kesehatan Republik Indonesia.

Kementerian Kesehatan Republik Indonesia. (2011a). Promosi kesehatan di daerah bermasalah kesehatan. Jakarta: Kementerian Kesehatan Republik Indonesia.

Kementerian Kesehatan Republik Indonesia. (2011b). Pedoman pembinaan perilaku hidup bersih dan sehat (PHBS). Jakarta: Kementerian Kesehatan Republik Indonesia.

Minarni, E.W., Utami, D.S., \& Prihatiningsih, N. (2017). Pemberdayaan Kelompok Wanita Tani Melalui Optimalisasi Pemanfaatan Pekarangan dengan Budidaya Sayuran Organik Dataran Rendah Berbasis Kearifan Lokal dan Berkelanjutan. Jurnal Pengabdian Dan Pemberdayaan Masyarakat, 1(2), 147154.

Prasanti, D., \& Fuady, I. (2017). Penyuluhan Program Literasi Informasi Kesehatan Dalam Meningkatkan Kualitas Sanitasi Bagi Masyarakat Di Kaki Gunung Burangrang Kab. Bandung Barat. Jurnal Pengabdian Dan Pemberdayaan Masyarakat, 1(2), 129-138.

Raksanagara, A. S., \& Raksanagara, A. (2015). Perilaku Hidup Bersih dan Sehat Sebagai Determinan Kesehatan yang Penting pada Tatanan Rumah Tangga di Kota Bandung. Jurnal Sistem Kesehatan, $1,30-34$.

Umar, Z. (2008). Perilaku Cuci Tangan Sebelum Makan dan Kecacingan Pada Murid SD di Kabupaten Pesisir Selatan Sumatera Barat. Jurnal Kesehatan 
Masyarakat Nasional, 2(6), 249-254.

Word Health Organization. (n.d.). Health literacy and health behaviour. Retrieved March 28, 2018, from http://www.who.int/healthpromotion/con ferences/7gchp/track2/en/ 